\title{
COMPLEMENTARY FEEDING PRACTICES OF CHILDREN AGED 12-23 MONTHS IN TURKEY
}

\author{
Eda Köksal' ${ }^{1}$ Sıddıka Songül Yalçın², Gülden Pekcan ${ }^{3}$, Sema Özbaş ${ }^{4}$, Başak Tezel ${ }^{4}$, Mehmet Rifat Köse \\ ${ }^{1}$ Department of Nutrition and Dietetics, Faculty of Health Science, Gazi University, Ankara, Turkey \\ ${ }^{2}$ Department of Paediatrics, Faculty of Medicine, Hacettepe University, Ankara, Turkey \\ ${ }^{3}$ Department of Nutrition and Dietetics, Faculty of Health Sciences, Hacettepe University, Ankara, Turkey \\ ${ }^{4}$ Maternal Child Health and Family Planning, Republic of Turkey Ministry of Health, Ankara, Turkey
}

\section{SUMMARY}

Aim: This study was conducted to determine the breastfeeding and complementary feeding attitudes and practices of women with children aged 12-23 months in three different regions in Turkey.

Methods: From 12 geographical regions (Nomenclature of Territorial Units for Statistics - NUTS 1), 3 regions were selected depending on the Turkish Demographic Health Survey 2003 (TDHS) results of nutritional status of children. Then, a weighted, multistage, stratified cluster sampling was used. In total, 1,486 children aged 12-23 months and mother pairs were enrolled. Mothers were face-to-face interviewed with trained health workers to collect information on breastfeeding practices, amount and types of complementary foods introduced and potentially related factors and demographic data filled in a questionnaire.

Results: The percentage of ever breastfeeding was $98.7 \%$, no differences were determined among regions for ever breastfeeding ( $p>0.05)$. Duration of exclusive breastfeeding was $5.1 \pm 2.4$ months. The shortest duration of exclusive breastfeeding was found in the good nutritional status region as $4.8 \pm 2.4$ months $(p<0.05)$. Yogurt, bread, pasta, fruits and vegetables were the foods introduced to the majority of the children. Red meat, poultry and fish were introduced to children in later ages in the low nutritional status region compared to middle and good nutritional status regions. Complementary feeding is introduced earlier than 6 months of age.

Conclusions: Raising awareness on appropriate infant and young child feeding practices should be a priority. Enhancing of mothers knowledge, attitudes and practices on breastfeeding and complementary feeding is needed.

Key words: breastfeeding, complementary feeding, complementary foods, feeding practices

Address for correspondence: E. Köksal, Gazi University of Health Science, Department of Nutrition and Dietetics, Besevler, 06500 Ankara, Turkey. E-mail: edakoksal@gazi.edu.tr

\section{INTRODUCTION}

The period from birth to two years of age is a "critical period" for the optimal growth, development and healthy life. This life period is the most important to prevent growth faltering, deficiencies of certain micronutrients, and common childhood illnesses. The immediate consequences of poor nutrition during the first two years include significant morbidity and mortality and delayed mental and motor development. In the long-term, early nutritional deficits are linked to impairments in intellectual performance; work capacity, reproductive outcomes and overall health during adolescence and adulthood period $(1,2)$.

Healthy infants should receive complementary feeding at the end of the first half-year of life. Since 2001, the World Health Organization has introduced recommendation on complementary foods at the sixth month of life $(1,3)$. Although the World Health Organization recommendation addresses all countries, advisory bodies in industrialized countries continue to recommend an age range for introduction of complementary foods. The European Society of Paediatric Gastroenterology, Hepatology and Nutrition (ESPGHAN) supports exclusive or full breast-feeding for about 6 months as a desirable goal and recommends that complementary feeding (i.e. solid foods and liquids other than breast milk or infant formula and follow-on formula) should not be introduced before 17 weeks and not later than 26 weeks (4). The American Academy of Pediatrics recommends that solid foods should not be introduced before 4 to 6 months of age (5).

Demographic and socioeconomic factors affect infant feeding practices. The socio-cultural influences on acceptable infant feeding practices are varied and complex, depending on the type of society. As a result of some of these practices, a large number of children especially in the developing world never experience proper feeding routines $(6,7)$.

Little is known about current patterns of feeding among Turkish infants during their first two years of life. This survey was conducted to determine the duration of breastfeeding and the starting age of complementary feeding in three regions of the Nomenclature of Territorial Units for Statistics (NUTS) NUTS - 1 in Turkey, previously determined and known as low, middle and good nutritional status according to the Turkish Demographic Health Survey 2003 (TDHS).

\section{MATERIAL AND METHODS}

\section{Study Design}

Mothers of children aged 12-23 months having birth weight $\geq 2,500 \mathrm{~g}$, and gestational age $\geq 37$ weeks from singleton preg- 
nancy and having neither major congenital anomalies nor chronic diseases were included into the survey. The survey was carried out from November 2006 to March 2007 with a community-based, cross-sectional survey using a weighted, multistage, stratified cluster sampling. Three of 12 NUTS -1 regions of Turkey were selected according to the prevalence of malnutrition (the percentages of height for age below 3SD; high, middle and low) in TDHS 2003 (8) and "Region with the highest malnutrition prevalence" was defined as low nutritional status region (LR), "region with middle malnutrition prevalence" as middle region (MR) and "region with the lowest malnutrition prevalence" as good region (GR) (9). Each region had 8 cities and these cities were listed from the worst to the best by using health indicators of the Turkish Government Planning Agency $(9,10)$ and the 2nd and the 8th city of each region were enrolled in the study (LR cities: Malatya and Bingol; MR cities: Hatay and Adana; GR cities: Bursa and Bilecik). Then, the Primary Health Care Centres of selected cities were listed and 32 centre-points were selected in each region by systematic sampling. Then 10 household clusters containing 30 households were chosen from each "selected Primary Health Care Centres" by systematic sampling. Afterwards, all the children meeting the inclusion criteria of the study (children aged 12-23 months) in each household-cluster were included in the survey.

\section{Data Collection}

In total, 1,486 mothers and their children (GR: 561, MR: 429 and LR: 496) aged 12-23 months were enrolled. Mothers were interviewed face-to-face by trained health workers to collect information on breastfeeding practices; amount and types of complementary foods (including traditional foods such as tarhana - fermented and dried flour and yogurt mixture used in preparing soup and pekmez - grape molasses) introduced and potentially affecting factors and demographic data filled in a questionnaire.

\section{Data Analysis}

Analysis of variance (ANOVA) and Kaplan-Meier analysis was used to compare the mean values on the duration of exclusive breastfeeding and timing of the introduction of complementary foods in the regions. A post-hoc Turkey correction for multiple comparisons was carried out to determine differences in groups. Chi-square test was used to compare the percentages of infants, given selected complementary foods at the 6th months of age among the regions. Data was analyzed using the Statistical Package for Social Sciences Software for Windows 10.0 (SPSS Inc. Chicago, IL, USA). The level of significance was set as $\mathrm{p}<0.05$.

\section{Ethical Consideration}

This survey was approved by the Ethical Committee of the Turkish Ministry of Health. Written informed consent was obtained from the mother of each child before enrolment.

\section{RESULTS}

A total of 1,486 mothers and their children $(53.4 \%$ boys and $46.6 \%$ girls) were included in the survey. Mean age of the chil- dren was $17.8 \pm 3.6$ months. The percentage of ever breastfeeding was $98.7 \%$. There was no difference among the regions for ever breastfeeding ( $p>0.05$ ). Overall, 90\% of children aged 12-23 months ate some yogurt, bread, pasta, fruits and vegetables. More than half of the infants were served eggs $(87 \%)$, poultry $(87 \%)$, beef or sheep meat $(83 \%)$, legumes $(82 \%)$, bulgur-cracked wheat (80\%), cow's milk (78\%), cheese (70\%), fish (67\%), pekmez (grape molasses) (63\%), and tarhana (fermented and dried flour and yogurt mixture used in preparing soup) (56\%). Nearly $33 \%$ of the children were given infant formula. Significantly lower percentages of infants consuming dairy products (cow's milk, yogurt and cheese), beef or sheep meat, eggs, legumes, fresh vegetables and fruits were found in low nutritional region than in other regions $(\mathrm{p}<0.05)$ (Table 1$)$.

Duration of exclusive breastfeeding was $5.2 \pm 2.4$ months. In GR, duration of exclusive breastfeeding was the shortest, as $4.8 \pm 2.4$ months $(p<0.05)$. When starting age of selected complementary foods were examined, red meat, poultry and fish were given in later ages in LR compared to MR and GR. Vegetable was introduced earlier in MR group than in other groups. Cow's milk was introduced later in GR and LR, however, eggs, cheese and tarhana earlier than in MR and LR groups. Grape molasses were started later in MR than in LR and GR groups $(\mathrm{p}<0.05)$ (Table 2).

Early introduction ( $<6$ months of age) of eggs, legumes, bread, tarhana, and grape molasses was found significantly more often in GR than in other regions $(p<0.05)$. However, cow's milk was given to fewer children in GR compared to other regions. Early introduction ( $<6$ months of age) of biscuits was noted more frequently in LR than in other regions $(p<0.05)$. Overall $45.9 \%$ of mothers served complementary food before 6 months and complementary feeding was given to lower number of children in LR than in other regions $(\mathrm{p}<0.05$, Table 3$)$.

\section{DISCUSSION}

Optimum nutrition and good infant feeding practices are among the most important determinants of health, growth and development in early life $(11,12)$. Despite the widespread acceptance of the superiority of breast milk over infant formula, less than $35 \%$ of infants worldwide are exclusively breastfed for the first 4 months of life, and complementary feeding practices are frequently inappropriate and unsafe (12). There is a widespread variation in infant feeding practices across Europe. For instance, breastfeeding initiation rates are relatively low and weaning occurs at an early age in the UK (13), however, breastfeeding is almost universal and weaning occurs at an older age in Scandinavian countries. Breastfeeding is almost universal in Turkey, according to the TDHS 2008 results, $97 \%$ of all children are breastfed for some period of time (14). Similarly, in this study the percentage of ever breastfeeding was $98.7 \%$ and there was no difference between the regions for ever breastfeeding. Despite the advice of the ESPGHAN Committee of Nutrition $(4,15)$, studies have showed that some mothers add supplementary foods earlier than recommended and that in Europe solid foods are introduced by the majority of mothers to infants aged between 8 weeks and 3 months and between 4 and 6 months (16). According to TDHS 2008 (14), more than one fifth of infants younger than two months are given infant formula in addition to breast milk in Turkey. In 
Table 1. Breastfeeding practices and complementary foods given to infants aged 12-23 months, in three regions, Turkey, $n$ (\%)

\begin{tabular}{|c|c|c|c|c|c|}
\hline & \multirow[b]{2}{*}{ Total } & \multicolumn{4}{|c|}{ Regions } \\
\hline & & GR & MR & LR & $p$ \\
\hline Ever breastfeeding & $1,467(98.7)$ & $557(99.3)$ & $420(97.9)$ & $490(98.8)$ & 0.198 \\
\hline Infant formula* & $482(32.5)$ & $259(46.3)^{a}$ & $91(21.2)^{b}$ & $132(26.6)^{b}$ & $<0.001$ \\
\hline Dairy products & $1,469(98.9)$ & $554(98.8)$ & $426(99.3)$ & $489(98.6)$ & 0.572 \\
\hline Cow's milk* & $1,150(77.4)$ & $456(81.3)^{a}$ & $349(81.4)^{a}$ & $345(69.6)^{b}$ & $<0.001$ \\
\hline Yogurt* & $1,308(88.0)$ & $493(87.9)^{\mathrm{a}}$ & $385(89.7)^{\mathrm{a}}$ & $430(86.7)^{b}$ & 0.004 \\
\hline Cheese $^{*}$ & $1,044(70.3)$ & $416(74.2)^{\mathrm{a}}$ & $314(73.2)^{\mathrm{a}}$ & $314(63.3)^{b}$ & 0.001 \\
\hline Meats, eggs, legumes & $1,444(97.2)$ & $551(98.2)^{a}$ & $420(97.9)^{a}$ & $473(95.4)^{b}$ & 0.011 \\
\hline Red meat* & $1,229(82.7)$ & $473(84.3)^{\mathrm{a}}$ & $374(87.2)^{a}$ & $382(77.0)^{b}$ & $<0.001$ \\
\hline Poultry* & $1,289(86.7)$ & $474(84.5)^{\mathrm{a}}$ & $402(93.7)^{b}$ & $413(83.3)^{a}$ & $<0.001$ \\
\hline Fish $^{*}$ & $1,001(67.4)$ & $457(81.5)^{b}$ & $283(66.0)^{\mathrm{a}}$ & $261(52.6)^{a}$ & $<0.001$ \\
\hline Eggs $^{*}$ & $1,290(86.8)$ & $503(89.7)^{a}$ & $373(86.9)^{a}$ & $414(83.5)^{b}$ & 0.010 \\
\hline Legumes & $1,213(81.6)$ & $476(84.8)^{\mathrm{a}}$ & $373(86.9)^{\mathrm{a}}$ & $364(73.4)^{b}$ & $<0.001$ \\
\hline Bread and cereals & $1,478(99.5)$ & $560(99.8)$ & $426(99.3)$ & $492(99.2)$ & 0.328 \\
\hline Bread $^{*}$ & $1,389(93.5)$ & $542(96.6)^{\mathrm{a}}$ & $401(93.5)^{\mathrm{a}}$ & $446(89.9)^{b}$ & 0.003 \\
\hline Rice $^{*}$ & $1,041(70.1)$ & $393(70.1)^{\mathrm{a}}$ & $362(84.4)^{\mathrm{a}}$ & $286(57.7)^{b}$ & $<0.001$ \\
\hline Bulgur* & $1,181(79.5)$ & $390(69.5)^{b}$ & $387(90.2)^{a}$ & $404(81.5)^{a}$ & $<0.001$ \\
\hline Pasta & $1,369(92.1)$ & $507(90.4)$ & $405(94.4)$ & 457 (92.1) & 0.084 \\
\hline Biscuits & $1,133(76.2)$ & $436(77.7)$ & $329(76.7)$ & 368 (74.2) & 0.485 \\
\hline Vegetables and fruits & $1,458(98.1)$ & $554(98.8)^{a}$ & $424(98.8)^{a}$ & $480(96.8)^{b}$ & 0.027 \\
\hline Vegetables* & $1,384(93.1)$ & $517(97.1)^{a}$ & $418(98.1)^{a}$ & $449(95.4)^{b}$ & 0.001 \\
\hline Fruits* & $1,388(93.4)$ & $532(94.8)^{a}$ & $413(96.3)^{\mathrm{a}}$ & $443(89.3)^{b}$ & $<0.001$ \\
\hline Traditional foods & $1,204(81.0)$ & $509(90.7)^{a}$ & $307(71.6)^{b}$ & $388(78.2)^{c}$ & $<0.001$ \\
\hline Tarhana* & $827(55.7)$ & $466(83.1)^{b}$ & $166(38.7)^{\mathrm{a}}$ & $194(39.3)^{a}$ & $<0.001$ \\
\hline Grape molasses* & $940(63.3)$ & $373(66.5)^{\mathrm{a}}$ & $240(55.9)^{b}$ & $327(65.9)^{a}$ & 0.001 \\
\hline
\end{tabular}

GR: Good region; MR: Middle region; LR: Low region

${ }^{*} p<0.05 ;$ a, b, cValues with different superscripts mean $p<0.05$, with the same superscripts mean $p>0.05$

this survey, exclusive breastfeeding period was $5.1 \pm 2.4$ months and this result was higher than the TDHS 2008 (14) results. Hizel et al. (17) reported in the study on 1,767 women between $15-49$ years of age in 10 provinces of Turkey that $35.8 \%$ of them started supplementary feeding in the first 3 months of life of the children.

The results of the study also show that the introduction of foods changes with the geographic region of family in Turkey. Exclusive breastfeeding period was found the shortest $(4.8 \pm 2.4$ months $)$ in good region $(\mathrm{p}<0.05)$. When timing of the introduction of complementary foods were compared among regions, infant formulas, cheese, eggs, bread, $100 \%$ fruit juice, and tarhana in GR and vegetables in MR were introduced earlier than in other areas $(p<0.05)$. Cow's milk was introduced at the latest in GR $(p<0.05)$. In addition, red meat, poultry and fish were introduced at the latest in LR, biscuits and molasses were introduced at the latest in MR. Similarly, the percentage of introduction of selected complementary foods were different according to regions in Turkey in the present study. For example, GR had the lowest percentage of served bulgur but highest percentage of introduction of fish and tarhana and, MR had lower percentage of served grape molasses which is a traditional food. Demirtas et al. (18) held a descriptive, qualitative study based on in-depth interviews, with a purposive sample of 24 mothers of 4 to 24 month old babies and showed that breastfeeding behaviour of mothers was mostly shaped by various cultural social and religious influences imposed on them by their family, close social network and religious community. ErgenekonOzelci et al. (19) found that $40 \%$ of mothers started solid foods before 4 months in 2001, in one of the LR city of Turkey. Saka et al. (20) reported that nearly all mothers had breastfed their infants at some time, but exclusive breastfeeding was rare and also, early introduction of sugared water, water and supplementary feeds was considered desirable among 921 mothers with children 6-18 months of age in a socio-economically disadvantaged region of Turkey. Also cultural variations affect the initial breastfeeding attitudes and practices of women. McLachlan and Forster (21), studied the cultural variations in the initial breastfeeding attitudes and practices of women born in Vietnam, Turkey and Australia who gave birth in Melbourne, Australia. Almost all Turkish women initiated breastfeeding (98\%) compared with $84 \%$ of Australian women. Vietnamese women had the lowest rate of breastfeeding initiation (75\%). Despite the Baby Friendly status of the hospital where the study was conducted, major differences were found in breastfeeding initiation.

Freeman et al. (13) reported that it was common for infants to receive their first solids, usually cereal-based, at around 3 months of age in the UK, whereas in Scandinavian countries pureed vegetables were usually the first foods introduced at around 6 months. In this survey, before the 6 months of age, yogurt 
Table 2. Average timing of the introduction of complementary foods and the duration of exclusive breastfeeding (months) in infants aged 12-23 months, in three regions, Turkey (Kaplan-Meier Analysis; estimated mean \pm SE)

\begin{tabular}{|c|c|c|c|c|}
\hline & & \multicolumn{3}{|c|}{ Regions } \\
\hline & Total & GR & MR & LR \\
\hline Exclusive breastfeeding* & $5.1 \pm 2.4$ & $4.8 \pm 2.4^{\mathrm{a}}$ & $5.3 \pm 2.6^{b}$ & $5.3 \pm 2.3^{b}$ \\
\hline \multicolumn{5}{|l|}{ Dairy products } \\
\hline Cow's milk* & $12.0 \pm 0.2$ & $12.0 \pm 0.3^{a}$ & $10.8 \pm 0.4^{b}$ & $12.8 \pm 0.4^{a}$ \\
\hline Yogurt & $8.1 \pm 0.1$ & $8.1 \pm 0.2$ & $8.1 \pm 0.2$ & $8.0 \pm 0.2$ \\
\hline Cheese $^{*}$ & $13.3 \pm 0.2$ & $12.2 \pm 0.3^{\mathrm{a}}$ & $13.1 \pm 0.4^{b}$ & $14.6 \pm 0.3^{c}$ \\
\hline \multicolumn{5}{|l|}{ Meats, eggs, legumes } \\
\hline Red meat $^{*}$ & $12.4 \pm 0.2$ & $12.0 \pm 0.2^{\mathrm{a}}$ & $11.5 \pm 0.3^{\mathrm{a}}$ & $13.4 \pm 0.3^{b}$ \\
\hline Poultry* & $11.7 \pm 0.1$ & $11.9 \pm 0.2^{\mathrm{a}}$ & $10.5 \pm 0.2^{b}$ & $12.5 \pm 0.2^{\mathrm{a}}$ \\
\hline Fish $^{*}$ & $15.0 \pm 0.2$ & $12.8 \pm 0.2^{\mathrm{a}}$ & $15.0 \pm 0.3^{b}$ & $17.4 \pm 0.3^{c}$ \\
\hline Eggs $^{*}$ & $10.8 \pm 0.2$ & $9.9 \pm 0.2^{\mathrm{a}}$ & $11.1 \pm 0.3^{b}$ & $11.5 \pm 0.3^{b}$ \\
\hline Legumes* & $12.6 \pm 0.2$ & $12.0 \pm 0.2^{\mathrm{a}}$ & $12.0 \pm 0.2^{\mathrm{a}}$ & $13.8 \pm 0.3^{b}$ \\
\hline \multicolumn{5}{|l|}{ Bread and cereals } \\
\hline Bread $^{*}$ & $9.8 \pm 0.1$ & $9.1 \pm 0.2^{\mathrm{a}}$ & $10.0 \pm 0.2^{b}$ & $10.5 \pm 0.2^{b}$ \\
\hline Rice $^{*}$ & $13.4 \pm 0.2$ & $13.3 \pm 0.3^{a}$ & $11.1 \pm 0.3^{b}$ & $15.1 \pm 0.4^{c}$ \\
\hline Bulgur* & $13.1 \pm 0.2$ & $14.7 \pm 0.3^{\mathrm{a}}$ & $11.3 \pm 0.2^{b}$ & $12.7 \pm 0.3^{c}$ \\
\hline Pasta* & $11.1 \pm 0.1$ & $11.4 \pm 0.2^{\mathrm{a}}$ & $10.7 \pm 0.2^{b}$ & $11.0 \pm 0.2^{a, b}$ \\
\hline Biscuits & $12.0 \pm 0.2$ & $11.6 \pm 0.3$ & $12.3 \pm 0.4$ & $12.1 \pm 0.3$ \\
\hline \multicolumn{5}{|l|}{ Vegetables and fruits } \\
\hline Vegetables* & $10.0 \pm 0.1$ & $10.2 \pm 0.2^{\mathrm{a}}$ & $9.0 \pm 0.2^{b}$ & $10.5 \pm 0.2^{\mathrm{a}}$ \\
\hline Fruits & $9.8 \pm 0.1$ & $9.6 \pm 0.2^{\mathrm{a}}$ & $9.6 \pm 0.2^{\mathrm{a}}$ & $10.4 \pm 0.3^{b}$ \\
\hline \multicolumn{5}{|l|}{ Traditional foods } \\
\hline Tarhana* & $15.7 \pm 0.2$ & $10.5 \pm 0.3^{\mathrm{a}}$ & $18.9 \pm 0.4^{b}$ & $18.8 \pm 0.3^{b}$ \\
\hline Grape molasses* & $14.5 \pm 0.2$ & $13.8 \pm 0.3^{a}$ & $16.1 \pm 0.4^{b}$ & $13.9 \pm 0.4^{a}$ \\
\hline
\end{tabular}

GR: Good region; MR: Middle region; LR: Low region

${ }^{*} p<0.05 ;{ }^{a, b, c}$ Values with different superscripts mean $p<0.05$

(16.6\%), infant formula (17.5\%) and cow's milk (14.9\%) were the mostly introduced complementary foods. According to regions, introducing time of all complementary foods except poultry, fish, rice, bulgur, pasta, and fruits were different. Infant feeding trends are associated with cultural differences and longstanding beliefs and practices (11). As expected, poor in the low nutritional status region (LR) consumed less meat, eggs, and legumes as well as yogurt and cheese. In some studies earlier introduction of complementary foods were found to be associated with lower socioeconomic status, education level and younger age of the mother $(6,22-24)$.

As a result, socioeconomic status, culture, climate, agricultural diversities, transportation and marketing of breast milk substitutes and solid foods might affect significantly nutritional status and habits in these regions. In this survey we only aimed to detect the regional differences in the starting age of different complementary foods. The effect of socio-demographic factors in the data will be analyzed in further studies. However, this study showed that living area influenced diversity of weaning and food consumption. Therefore, no matter what causes eating habits that lead to differences, training programmes should be planned taking into account regional differences. Improvements in the nutritional status of infants could be achieved by counselling on the correct timing of introduction of appropriate and achievable complementary foods.
The World Health Organization (WHO) recommends that all infants should be exclusively breastfed from birth to six months of age followed by continued breastfeeding and the gradual introduction of solids (1). In Turkey, these recommendations are supported by health policy makers. Traditionally, in Turkey almost all women breastfeed but complementary feeding is introduced earlier than recommended.

\section{CONCLUSIONS}

In conclusion, appropriate educational interventions on breastfeeding and complementary feeding are important in order to improve existing infant feeding practices. The educational strategies should focus particularly on counteracting the traditional beliefs and practices. Complementary foods offered before six months of age tend to displace breast milk and do not confer any growth advantage over exclusive breastfeeding. Breastfeeding promotion in the community should target not only mothers, but also other family members. To promote breastfeeding practices, it is vital to improve the counselling skills of health professionals. The development, implementation, monitoring and evaluation of overarching national breastfeeding and introduction of complementary feeding strategy 
Table 3. Distribution of early introduction (<6 mo) of complementary foods, $n$ (\%)

\begin{tabular}{|c|c|c|c|c|c|}
\hline & \multirow[b]{2}{*}{ Total } & \multicolumn{4}{|c|}{ Regions } \\
\hline & & GR & MR & LR & $p$ \\
\hline Infant formula* & $260(17.5)$ & $148(26.4)$ & $56(13.1)$ & $56(11.3)$ & $<0.001$ \\
\hline Dairy products & $426(28.7)$ & $145(25.8)^{a}$ & $144(33.6)^{b}$ & $137(27.6)^{b}$ & 0.024 \\
\hline Cow milk* & $222(14.9)$ & $42(7.5)^{\mathrm{a}}$ & $89(20.7)^{b}$ & $91(18.3)^{b}$ & $<0.001$ \\
\hline Yogurt* & $247(16.6)$ & $106(18.9)^{a}$ & $75(17.5)^{a, b}$ & $66(13.3)^{b}$ & 0.044 \\
\hline Cheese $^{*}$ & $56(3.8)$ & $32(5.7)^{\mathrm{a}}$ & $21(4.9)^{\mathrm{a}}$ & $3(0.6)^{b}$ & $<0.001$ \\
\hline Meats, eggs, legumes & $90(6.1)$ & $42(7.5)^{\mathrm{a}}$ & $34(7.9)^{a}$ & $14(2.8)^{b}$ & 0.001 \\
\hline Red meat & $22(1.5)$ & $11(2.0)$ & $6(1.4)$ & $5(1.0)$ & 0.435 \\
\hline Poultry & $20(1.3)$ & $9(1.6)$ & $8(1.9)$ & $3(0.6)$ & 0.202 \\
\hline Fish* & $8(0.5)$ & $7(1.2)^{a}$ & $1(0.2) b$ & - & 0.013 \\
\hline Eggs* $^{*}$ & $60(4.0)$ & $28(5.0)^{\mathrm{a}}$ & $25(5.8)^{a}$ & $7(1.4)^{b}$ & 0.001 \\
\hline Legumes & $14(0.9)$ & $7(1.2)$ & $6(1.4)$ & $1(0.2)$ & 0.109 \\
\hline Bread and cereals & $222(14.9)$ & $78(13.9)^{a}$ & $72(16.8)^{\mathrm{a}}$ & $72(14.5)^{\mathrm{a}}$ & 0.429 \\
\hline Bread & $39(2.6)$ & $12(2.1)$ & $13(3.0)$ & $14(2.8)$ & 0.647 \\
\hline Rice $^{*}$ & $111(7.5)$ & $31(5.5)^{\mathrm{a}}$ & $43(10.0)^{b}$ & $37(7.5)^{a, b}$ & 0.029 \\
\hline Bulgur* & $11(0.7)$ & $1(0.2)^{a}$ & $10(2.3)^{b}$ & - & $<0.001$ \\
\hline Pasta* & $15(1.0)$ & $4(0.7)^{\mathrm{a}, \mathrm{b}}$ & $10(2.3)^{b}$ & $1(0.2)^{a}$ & 0.004 \\
\hline Biscuits & $119(8.0)$ & $42(7.5)^{\mathrm{a}}$ & $39(9.1)^{a}$ & $38(7.7)^{b}$ & 0.615 \\
\hline Vegetables and fruits & $136(9.2)$ & $58(10.3)^{\mathrm{a}}$ & $47(11.0)^{\mathrm{a}}$ & $31(6.3)^{b}$ & 0.022 \\
\hline Vegetables* & $41(2.8)$ & $11(2.0)^{\mathrm{a}}$ & $23(5.4)^{b}$ & $7(1.4)^{\mathrm{a}}$ & $<0.001$ \\
\hline Fruits & $75(5.0)$ & $30(5.3)$ & $23(5.4)$ & $22(4.4)$ & 0.748 \\
\hline Traditional foods & $108(7.3)$ & $48(8.6)^{\mathrm{a}}$ & $16(3.7)^{b}$ & $44(8.9)^{\mathrm{a}}$ & 0.004 \\
\hline Tarhana* & $32(2.2)$ & $27(4.8)^{\mathrm{a}}$ & $4(0.9)^{b}$ & $1(0.2)^{b}$ & $<0.001$ \\
\hline Grape molasses* & $80(5.4)$ & $23(4.1)^{\mathrm{a}}$ & $14(3.3)^{a}$ & $43(8.7)^{b}$ & $<0.001$ \\
\hline Total complementary feeding & $682(45.9)$ & $281(50.1)^{a}$ & $202(47.1)^{a}$ & $199(40.1)^{b}$ & 0.004 \\
\hline
\end{tabular}

GR: Good region; MR: Middle region; LR: Low region

${ }^{*} p<0.05 ;{ }^{a, b}$ Values with different superscripts mean $p<0.05$

are fundamental to achieving significant improvements in breastfeeding practices.

The limitation of this study is that it was focused on 2006-2007 years so the similar studies to show the changes over the years are required. However, this is the largest study on this issue and little information has been published about feeding habits of Turkish young children.

\section{Acknowledgements}

The authors are grateful to the mothers and infants for the willingness to participate in the study. Authors are also indebted to the thousands of health workers and doctors of primary health care centres whose dedication and effort made this project possible; to the Advisory Board of "Turkey like iron" programme of the Turkish Ministry of Health for the encouragement and support of this project.

\section{Conflict of Interests}

None declared

\section{Funding}

The authors disclosed the cost was supported partially by the ADEKA, Abdi İbrahim, Santa Farma.

\section{REFERENCES}

1. Dewey K. Guiding principles for complementary feeding of the breastfed child. Washington, D.C.: Pan American Health Organization; 2001.

2. Guiding principles for feeding non-breastfed children 6-24 months of age. Geneva: World Health Organization; 2005.

3. Indicators for assessing infant and young child feeding practices. Part 1 Definitions: conclusions of a consensus meeting held 6-8 November 2007 in Washington D.C., USA. Geneva: World Health Organization, 2008.

4. Agostoni C1, Decsi T, Fewtrell M, Goulet O, Kolacek S, Koletzko B, et al; ESPGHAN Committee on Nutrition. Complementary feeding: a commentary by the ESPGHAN Committee on Nutrition. J Pediatr Gastroenterol Nutr. 2008 Jan;46(1):99-110.

5. Greer FR, Sicherer SH, Burks AW; American Academy of Pediatrics Committee on Nutrition; American Academy of Pediatrics Section on Allergy and Immunology. Effects of early nutritional interventions on the development of atopic disease in infants and children: the role of maternal dietary restriction, breastfeeding, timing of introduction of complementary foods, and hydrolyzed formulas. Pediatrics. 2008 Jan;121(1):183-91.

6. Schiess S, Grote V, Scaglioni S, Luque V, Martin F, Stolarczyk A, et al. Introduction of complementary feeding in 5 European countries. J Pediatr Gastroenterol Nutr. 2010 Jan;50(1):92-8.

7. Sika-Bright $\mathrm{S}$. Socio-cultural factors influencing infant feeding practices of mothers attending welfare clinic in Cape Coast [Internet]. Ibadan: IFRA-Nigeria, 2010 [cited 2011 Jun 20]. Available from: http://www. ifra-nigeria.org/IMG/pdf/Sika.pdf.

8. Turkey Demographic and Health Survey, 2003. Ankara: Hacettepe University Institute of Population Studies, 2004.

9. Yalçın SS, Pekcan G, Tezel B, Köksal E, Özbaş S, Yurdakök K, et al. Research report is iron supplement use in children aged 12-23 months. 
Ankara: Ana Çocuk Sağlığı Aile Planlaması Genel Müdürlüğü Matbaası, 2009. (In Turkish.)

10. Dinçer B, Özaslan M, Kavasoğlu T. Cities and Regions of Socio-economic Development Ranking Survey 2003. Ankara: Republic of Turkey, Ministry of Development, 2003. (In Turkish.)

11. Michaelsen KF, Weaver L, Branca F, Robertson A. Feeding and nutrition of infants and young children. Guidelines for the WHO European Region with emphasis on former Soviet countries. Copenhagen: WHO Regional Publications; 2000. European Series, No. 87.

12. Global strategy for infant and young child feeding. The optimal duration of exclusive breastfeeding [Internet]. Geneva: World Health Organization, 2001 [cited 2011 Jun 20]. Avalaible from: http://apps.who.int/gb/archive/ pdf files/WHA54/ea54id4.pdf.

13. Freeman V1, van't Hof M, Haschke F. Patterns of milk and food intake in infants from birth to age 36 months: the Euro-growth study. J Pediatr Gastroenterol Nutr. 2000;31 Suppl 1:S76-85.

14. Turkey Demographic and Health Survey, 2008. Ankara: Hacettepe University Institute of Population Studies, 2009.

15. ESPGHAN Committee on Nutrition, Agostoni C, Braegger C, Decsi T, Kolacek S, Koletzko B, et al. Breast-feeding: a commentary by the ESPGHAN Committee on Nutrition. J Pediatr Gastroenterol Nutr. 2009 Jul;49(1):112-25.

16. Synott K, Bogue J, Edwards CA, Scott JA, Higgins S, Norin E, et al. Parental perceptions of feeding practices in five European countries: an exploratory study. Eur J Clin Nutr. 2007 Aug;61(8):946-56.

17. Hizel S, Ceyhun G, Tanzer F, Sanlı C. Traditional beliefs as forgotten influencing factors on breast-feeding performance in Turkey. Saudi Med J. 2006 Apr;27(4):511-8.
18. Demirtas B, Ergocmen B, Taskin L. Breastfeeding experiences of Turkish women. J Clin Nurs. 2012 Apr;21(7-8):1109-18.

19. Ergenekon-Ozelci P, Elmaci N, Ertem M, Saka G. Breastfeeding beliefs and practices among migrant mothers in slums of Diyarbakir, Turkey, 2001. Eur J Public Health. 2006 Apr;16(2):143-8.

20. Saka G, Ertem M, Musayeva A, Ceylan A, Kocturk T. Breastfeeding patterns, beliefs and attitudes among Kurdish mothers in Diyarbakir, Turkey. Acta Paediatr. 2005 Sep;94(9):1303-9.

21. McLachlan HL, Forster DA. Initial breastfeeding attitudes and practices of women born in Turkey, Vietnam and Australia after giving birth in Australia. Int Breastfeed J. 2006 Apr 7;1:7.

22. Alder EM, Williams FL, Anderson AS, Forsyth S, Florey Cdu V, van der Velde $\mathrm{P}$. What influence the timing of the introduction of solid food to infants? Br J Nutr. 2004 Sep;92(3):527-31.

23. Lande B, Andersen LF, Baerug A, Trygg KU, Lund-Larsen K, Veierød $\mathrm{MB}$, et al. Infant feeding practices and associated factors in the first six months of life: the Norwegian infant nutrition survey. Acta Paediatr. 2003;92(2):152-61.

24. Wright CM, Parkinson KN, Drewett RF. Why are babies weaned early? Data from a prospective population based cohort study. Arch Dis Child. 2004 Sep;89(9):813-6. 